\title{
CADMIUM-INDUCED CHANGES IN HATCHABILITY AND \\ IN THE ACTIVITY OF AMINOTRANSAMINASES AND SELECTED LYSOSOMAL HYDROLASES IN THE BLOOD PLASMA OF MUSCOVY DUCKLINGS (CAIRINA MOSCHATA)
}

\author{
Małgorzata DżUGAN ${ }^{1 *}$ and Marcin LIs ${ }^{2}$ \\ ${ }^{1}$ Department of Chemistry and Food Toxicology, University of Rzeszów, Ćwiklińskiej 2, \\ 35-601 Rzeszów, Poland; ${ }^{2}$ Department of Veterinary and Animal Reproduction and \\ Welfare, University of Agriculture in Krakow, Kraków, Poland
}

(Received 14 July 2015; accepted 28 October 2015)

\begin{abstract}
The aim of this study was to determine the effect of cadmium on Muscovy ducklings (Cairina moschata) based on hatching results and the activity of enzymes in the blood plasma. On day 6 of incubation, hatching eggs were injected into the egg albumen with $50 \mu \mathrm{l}$ of saline solution containing $\mathrm{Cd}$ ions $\left(\mathrm{CdCl}_{2}\right)$ at concentrations of 0 (control group), 1.3, 4.0, 7.5, 15.0 and $30 \mu \mathrm{g} / \mathrm{egg}$, using 50 eggs per group. A gradual decrease in hatchability, from $52 \%$ in the control to $4 \%$ in the highest Cd dose group, was observed, with the $\mathrm{LD}_{50}$ calculated as $8 \mu \mathrm{g} / \mathrm{egg}$. However, the impact of cadmium on the incidence of malformations of duck embryos has not been proven. Compared to the control group, N-acetyl- $\beta$-Dglucosaminidase activity increased by $30-50 \%(\mathrm{P} \leq 0.05)$ in the blood serum of ducklings in the groups receiving more than $7.5 \mu \mathrm{g} \mathrm{Cd} / \mathrm{egg}$, whereas an elevated activity of arylsulphatase (by $45 \%$ ) was observed for a lower dose only (4 $\mu \mathrm{g}$ $\mathrm{Cd} /$ egg). A gradual increase in the activity of alanine and aspartate aminotransferases was observed $(\mathrm{P} \leq 0.05)$, starting from the lowest exposure of $1.3 \mu \mathrm{g}$ $\mathrm{Cd} / \mathrm{egg}$, by $155 \%$ and $53 \%$, respectively. In conclusion, the results prove the dosedependent toxic impact of cadmium on embryogenesis and on the studied blood plasma enzyme activities of ducklings.
\end{abstract}

Key words: Muscovy duck, embryogenesis, cadmium, aminotransferases, lysosomal hydrolases

Cadmium is a ubiquitous trace metal and human activities appear to have increased its abundance in the biosphere during the past several decades. The human population and animals are exposed to Cd via contaminants found in air, drinking water and food that tend to accumulate slowly in the body (Järup et al., 1998; Satarug et al., 2003). Various organs can accumulate Cd, mainly the liver and the kidneys (Dżugan et al., 2012b; Sarkar et al., 2013). Exposure to cadmium has been associated with numerous harmful effects on several organs including

*Corresponding author; E-mail: mdzugan@ur.edu.pl; Phone: 0048 (17) 872-1722 
the kidneys, liver, lung, pancreas, testis, placenta, as well as on bone structure and physiological functions (Sarkar et al., 2013; Marettová et al., 2015). Indeed, Cd inhibits the mitochondrial electron transfer chain and induces the production of reactive oxygen species (ROS), leading to DNA strand damage (Wang et al., 2004).

Several toxicological impacts due to cadmium ingestion have been reported in birds and mammals. Among them, exposure to cadmium induces a decrease in fertility and embryonic development, and also causes prenatal death and sexual dysfunction. In the few studies conducted on birds, the in situ levels of heavy metals in wild populations were investigated (Kalisińska et al., 2004; Lucia et al., 2010; Dżugan et al., 2012b). As the reproductive system of birds is particularly sensitive to chemical environmental pollutants (Marettová et al., 2015), avian eggs and embryos are considered to be sensitive indicators of heavy metal contamination (Dobrzański et al., 2004; Thompson et al., 2010; Kim and $\mathrm{Oh}, 2014)$. Moreover, cadmium has negative effects on fertility and early embryo development. The adverse action of cadmium on embryogenesis in chicken (Dżugan et al., 2011, 2012a; Yamamoto et al., 2012; Pawlak et al., 2013; Kensova et al., 2015) and aquatic birds (Kertész and Fáncsi, 2003) has been intensively studied. The rapid movement of contaminants in the aquatic environment increases the risk for aquatic birds as compared to terrestrial ones.

The accumulation of chemicals present at low concentrations in water or the sediment can be biomagnified, reaching harmful concentrations in the tissues of higher-level consumers (Tsipoura et al., 2011). The effects of heavy metal compounds on aquatic birds have been widely investigated in ecotoxicological studies which, however, mainly focus on the postnatal period of life (Lucia et al., 2010; Tsipoura et al., 2011). Birds exposed to high environmental contaminant levels accumulate heavy metals in their eggs (0-200 and 20-6700 ppm for $\mathrm{Pb}$ and $\mathrm{Cd}$, respectively) (Tsipoura et al., 2011). Moreover, the eggs of waterfowl may come into direct contact with different surface pollutants, transferred by immersion during the nesting season (Kertész and Fáncsi, 2003). However, less information is available on the adverse effect of cadmium on embryonic development in waterfowl. Therefore, the objective of this study was to evaluate the effects of cadmium on the embryonic development of Muscovy duck (Cairina moschata) and on the biochemical status of hatched ducklings.

\section{Materials and methods}

The experimental and animal procedures were approved by the First Local Ethics Committee at the Medical University in Lublin, Poland (No. 9/2011). Hatching eggs of Muscovy ducks (Cairina moschata) $(\mathrm{n}=320)$, weighing $87.3 \pm$ $10.42 \mathrm{~g}$ and originating from a parent stock farm (Drop S.A. Kępno, Poland), were used. The eggs were incubated in a Masalles 65 DIGIT incubator under 
standard conditions [incubation days E1-E28: temperature $(\mathrm{T})=37.8^{\circ} \mathrm{C}$, relative humidity $(\mathrm{RH})=50 \%$; E29-E34: $\mathrm{T}=37.2 \pm 0.1{ }^{\circ} \mathrm{C}$; $\left.\mathrm{RH}=65 \%\right]$. On day 6 of incubation (E6) the eggs were candled and embryonated eggs $(n=50$ eggs per group) were injected with $\mathrm{CdCl}_{2}$ (Sigma, USA) solution into the egg albumen under the chorioallantoic membrane. Doses containing 0, 1.3, 4.0, 7.5, 15.0 and $30.0 \mu \mathrm{g} \mathrm{Cd} / 50 \mu \mathrm{l}$ were used. The doses were analogous to those used in an earlier experiment (Dżugan et al., 2011) based on the weight of the duck eggs.

The eggs were candled again on days 10 (E10) and 28 (E28) of incubation and those with dead embryos were eliminated. All eggs discarded during candling or unhatched from the 'hatchability' subgroups were analysed for the stage of development and malformations (Romanoff, 1972). Based on hatchability results, the lethal dose $\left(\mathrm{LD}_{50}\right)$ was calculated by the Spearman-Kärber method (Hamilton et al., 1977).

Immediately after hatching, the ducklings were weighed, and blood was collected into heparinised tubes from the jugular vein of all hatched ducklings from each group after decapitation, excluding the $30 \mu \mathrm{g}$ Cd group due to its very low hatchability. The blood was centrifuged and the plasma was stored at $-20{ }^{\circ} \mathrm{C}$ until biochemical analyses. The blood plasma was assayed spectrophotometrically for the activity of lysosomal hydrolases $\mathrm{N}$-acetyl- $\beta$-D-glucosaminidase (NAG), $\beta$-D-galactosidase ( $\beta$-GAL), $\beta$-D-mannosidase $(\beta$-MAN), $\alpha$-D-galactosidase $(\alpha$ GAL), $\alpha$-D-fucosidase ( $\alpha$-FUC), $\alpha$-D-glucosidase ( $\alpha$-GLU), and arylsulphatase (ARYL) using appropriate substrates as described earlier (Dżugan et al., 2011). The activities of alanine aminotransferase (ALT) and aspartate transferase (AST) were determined by the kinetic method using commercial kits (Alpha Diagnostics, Poland).

The hatchability and embryo-pathological results were statistically analysed by z-test while the results of enzyme activities by one-way analysis of variance (ANOVA) followed by Tukey's multiple range test. The tendencies of enzymatic activities were also calculated. The statistical analyses were performed using Sigma-Stat 3.5 (SPSS Science Software Ltd., USA) and the figures were prepared using Grapher 8.0 (Golden Software Inc., USA).

\section{Results}

The hatchability of ducklings gradually decreased after in ovo cadmium injection on E6, from $52 \%$ in the control group to $4 \%$ in the group exposed to $30 \mu \mathrm{g} \mathrm{Cd} /$ egg (Table 1), and the median lethal dose $\left(\mathrm{LD}_{50}\right)$ was calculated as $8 \mu \mathrm{g} \mathrm{Cd} / \mathrm{egg}$. Moreover, the relationship between cadmium dose and hatchability can be described by the equation $y=48.70-2.79 x+0.16 x^{2}-0.004 x^{3}\left(r^{2}=0.907\right.$, $\mathrm{P} \leq 0.05)$, where $\mathrm{y}=$ percentage of hatched ducklings in relation to eggs with live embryos at injection; $\mathrm{x}=$ cadmium dose in $\mu \mathrm{g} / \mathrm{egg}$ (Fig. 1). 


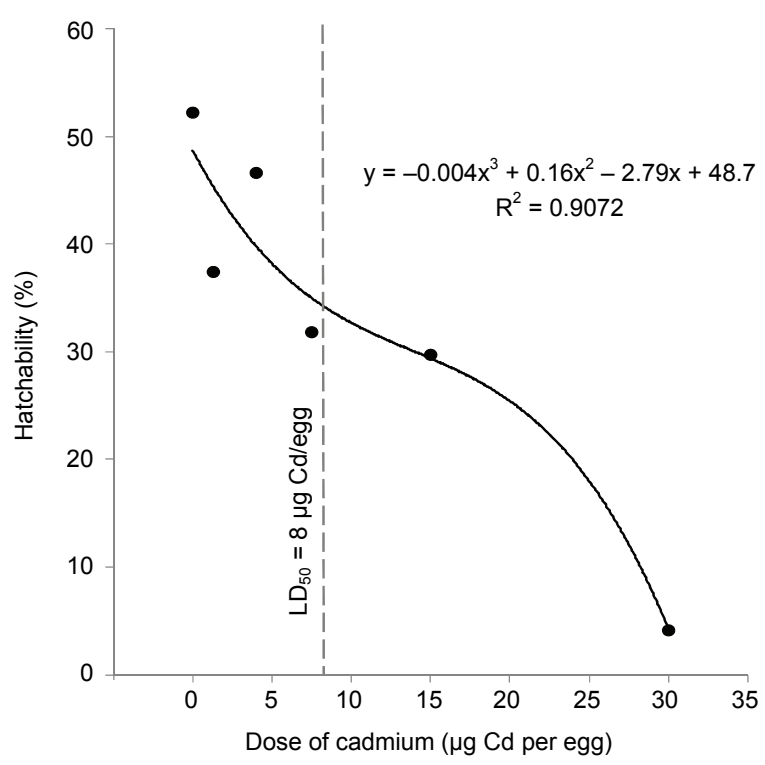

Fig. 1. Relationship between cadmium dose injected in ovo on day 6 of incubation and hatchability of ducklings (Cairina moschata)

Exposure to increasing doses of cadmium ions from 0 to $30 \mu \mathrm{g}$ per egg increased mortality, particularly within $48 \mathrm{~h}$ of injection, by 4 to $96 \%$ (Table 1). However, low exposure (1.3 Cd per egg) increased the mortality of embryos during hatching, which was mainly due to malpositions but not malformations (Table 2).

The body weight (BW) of hatched ducklings was $50.4 \pm 6.6 \mathrm{~g}$ for males and $47.7 \pm 7.1 \mathrm{~g}$ for females $(\mathrm{P} \leq 0.05)$, and no effect of cadmium administration on body weight was observed ( $\mathrm{P}>0.05)$. The liver weight standardised to body weight was about $2.7 \%$ and it did not differ between genders $(\mathrm{P}>0.05)$ and experimental groups $(\mathrm{P}>0.05)$.

\section{Table 1}

The effect of Cd (II) ions injected in ovo on day 6 of incubation on embryo mortality and hatching results of Muscovy duck (Cairina moschata)

\begin{tabular}{lcccccc}
\hline & \multicolumn{5}{c}{ Cadmium dose ( $\mu$ g per egg) } \\
\cline { 2 - 7 } & 0 & 1.3 & 4.0 & 7.5 & 15.0 & 30.0 \\
\hline Group size (n) & 50 & 50 & 50 & 50 & 50 & 50 \\
Deaths after injection (E6-E9) (\%) & $4.0^{\mathrm{a}}$ & $4.0^{\mathrm{a}}$ & $16.0^{\mathrm{b}}$ & $22.0^{\mathrm{ab}}$ & $26.0^{\mathrm{b}}$ & $96.0^{\mathrm{c}}$ \\
Deaths from E10 to E28 (\%) & $10.0^{\mathrm{ab}}$ & $4.0^{\mathrm{ac}}$ & $6.0^{\mathrm{a}}$ & $12.0^{\mathrm{ab}}$ & $14.0^{\mathrm{b}}$ & $0.0^{\mathrm{c}}$ \\
Deaths during the hatching period (E29-E32) (\%) & $34.0^{\mathrm{b}}$ & $54.0^{\mathrm{a}}$ & $32.0^{\mathrm{b}}$ & $34.0^{\mathrm{b}}$ & $30.0^{\mathrm{b}}$ & $0.0^{\mathrm{c}}$ \\
Hatchability (\%) & $52.0^{\mathrm{a}}$ & $38.0^{\mathrm{abc}}$ & $46.0^{\mathrm{ab}}$ & $32.0^{\mathrm{bc}}$ & $30.0^{\mathrm{c}}$ & $4.0^{\mathrm{d}}$ \\
\hline
\end{tabular}

$\mathrm{E}=$ incubation days; abcd - values marked with different superscript letters within a row differ significantly $(\mathrm{P} \leq 0.05)$ 
Table 2

The occurrence of malpositions and malformations of Muscovy duck (Cairina moschata) embryos after in ovo administration of Cd (II) ions on day 6 of incubation

\begin{tabular}{|c|c|c|c|c|c|c|}
\hline & \multicolumn{6}{|c|}{ Cadmium dose ( $\mu$ g per egg) } \\
\hline & 0 & 1.3 & 4 & 7.5 & 15 & 30 \\
\hline Embryos live at E29 & 43 & 46 & 39 & 33 & 29 & 2 \\
\hline Hatched chicks & 26 & 19 & 23 & 16 & 15 & 2 \\
\hline \multicolumn{7}{|c|}{ Embryos dead between incubation days E29 and E32 } \\
\hline Unable to internally pip & 12 & 11 & 10 & 11 & 9 & - \\
\hline During internal pipping & 3 & 5 & 2 & 5 & 2 & - \\
\hline During external pipping & 2 & 2 & 4 & 1 & 4 & - \\
\hline Total & 17 & 27 & 16 & 17 & 15 & - \\
\hline \multicolumn{7}{|c|}{ Malpositions } \\
\hline Not detected & 13 & 19 & 13 & 13 & 13 & - \\
\hline Head between thighs & - & - & - & 2 & - & - \\
\hline Head in small end & - & 2 & 1 & & - & - \\
\hline Head under left wing & - & 1 & - & & - & - \\
\hline Feet over head & 1 & 2 & - & & 1 & - \\
\hline Head over right wing & 1 & 1 & 2 & 1 & 1 & - \\
\hline Transverse position in egg & 2 & 2 & - & 1 & - & - \\
\hline Total & 4 & 8 & 3 & 4 & 2 & - \\
\hline \multicolumn{7}{|c|}{ Malformations ${ }^{*}$} \\
\hline Dwarfism & 1 & 2 & - & 1 & 2 & - \\
\hline Encephalocele & - & - & - & 2 & - & - \\
\hline Swelling of the head & - & - & - & 2 & - & - \\
\hline Total & 1 & 2 & - & 5 & 2 & - \\
\hline
\end{tabular}

* Detected in embryos dead between E6 and E32

The majority of tested enzymes showed changes dependent on increasing cadmium dose (Table 3). Compared to the control group, in the blood serum of ducklings from the groups receiving 4, 7.5 and $15 \mu \mathrm{g} \mathrm{Cd} / \mathrm{egg}$ ARYL activity increased by 45, $26(\mathrm{P} \leq 0.05)$ and 17\% $(\mathrm{P}>0.05)$, respectively. Among glycosidases, NAG and $\alpha$-GAL showed the highest sensitivity to cadmium. The activity of these enzymes increased by $30-50 \%$ for exposure to 7.5 and $15 \mu \mathrm{g} \mathrm{Cd} / \mathrm{egg}$ $(\mathrm{P} \leq 0.05)$ as compared to the control group. In the case of $\alpha$-MAN, $\beta$-MAN and $\beta$-GAL, significant changes in activity (about 43,34 and $21 \%$, respectively) were observed only for the $7.5 \mu \mathrm{g} \mathrm{Cd} / \mathrm{egg}$ dose. $\alpha$-GLU and $\alpha$-FUC activities were not cadmium dependent $(\mathrm{P}>0.05)$. 


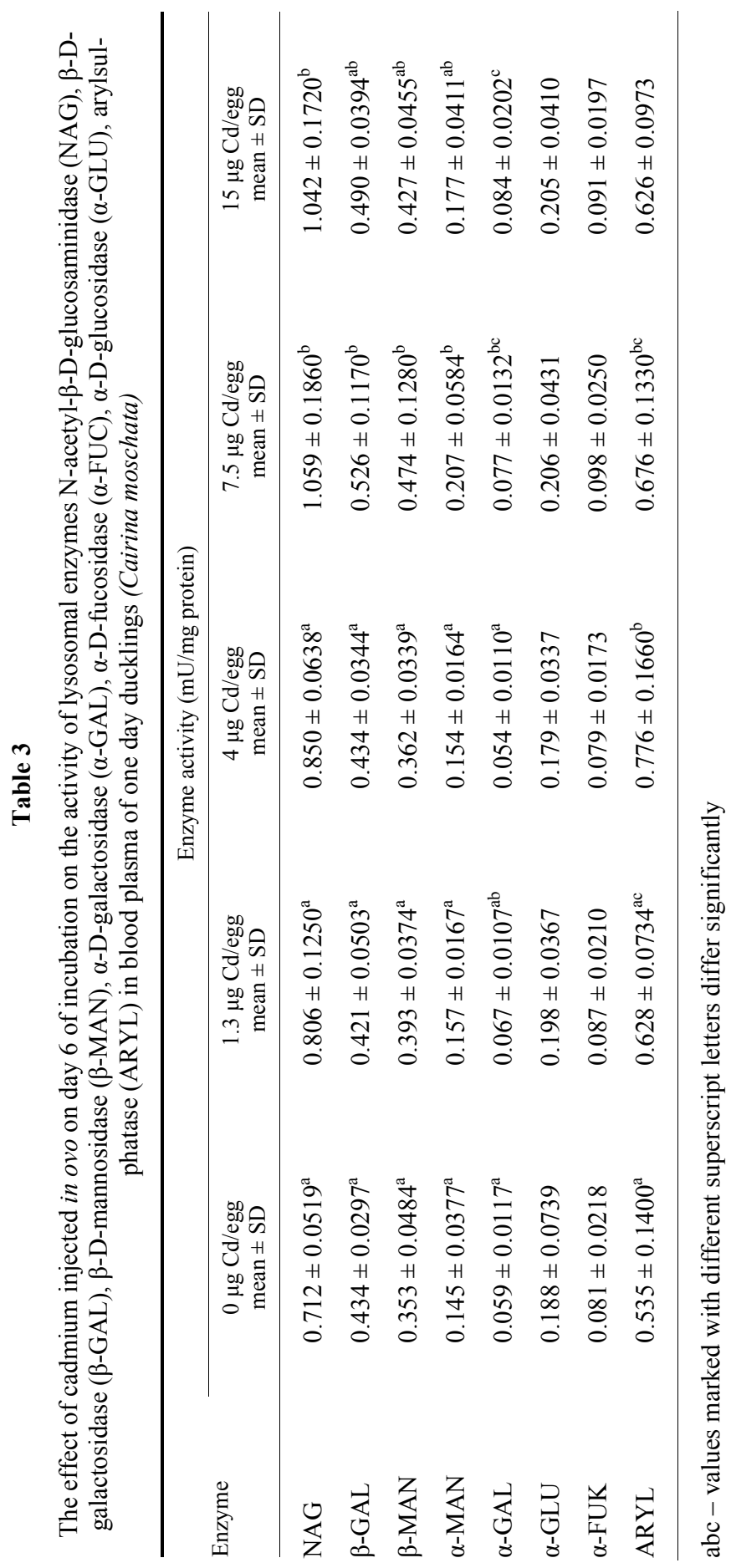


Simultaneously, the lowest dose of $\mathrm{Cd}$ ions resulted in elevated activities of serum transaminases. As compared to the control group, significant increases in ALT (by 155, 209, 194 and 73\%) and AST (by 53, 33, 78 and 80\%) activities were observed for the 1.3, 4, 7.5 and $15 \mu \mathrm{g} \mathrm{Cd} /$ egg doses, respectively (Fig. 2).
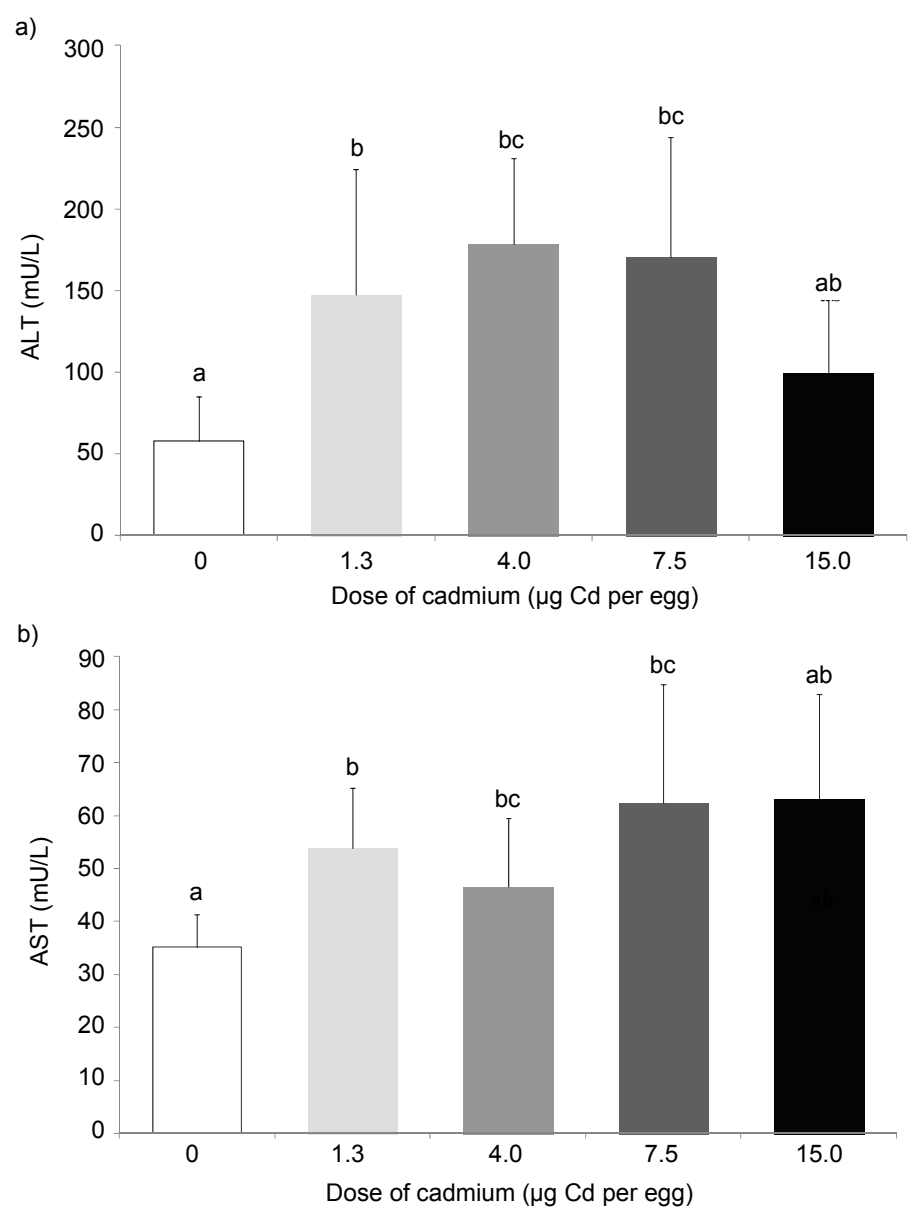

Fig. 2. The effect of cadmium injected in ovo on day 6 of incubation on activity changes of (a) alanine aminotransferase (ALT) and (b) aspartate aminotransferase (AST) in the blood plasma of one-day-old ducklings (Cairina moschata)

\section{Discussion}

The results indicate that the introduction of cadmium into the eggs at doses exceeding $1.3 \mu \mathrm{g} / \mathrm{egg}$ caused a gradual decrease in hatchability, with an $\mathrm{LD}_{50}$ of $8 \mu \mathrm{g} \mathrm{Cd} / \mathrm{egg}$. This is consistent with the level of $0.3-1.2 \mu \mathrm{g} \mathrm{Cd}$ per egg which was shown to have no effect on the hatching results in chicken (Sato et al., 
1997; Dżugan et al., 2011). In nature, this level of egg contamination of wild (Tsipoura et al., 2011) and domestic birds (Sato et al., 1997; Lucia et al., 2010; Kim and Oh, 2014) is usually not exceeded because the transfer of toxic metal ions from the environment into eggs is strongly limited by a highly specific barrier between the oviduct and the egg (Sato et al., 1997; Rahman et al., 2007). On the other hand, a low but permanent cadmium content (1.3 ppm) of drinking water and/or food can significantly decrease egg production and weight as well as hatchability in hens (Vodela et al., 1997), pheasants (Toman et al., 2005), and ducks (Lucia et al., 2010). However, in contaminated areas the amount of cadmium in chicken eggs may exceed $4.0 \mu \mathrm{g} / \mathrm{egg}(71 \mu \mathrm{g} \mathrm{Cd}$ per $\mathrm{kg}$ of egg) as compared with the average level, which is about $0.1-0.8 \mu \mathrm{g} /$ egg (Dobrzański et al., 2004). The $\mathrm{LD}_{50}$ calculated in the experiment described here $(8 \mu \mathrm{g} \mathrm{Cd} / \mathrm{egg}$ which amounts to $91.6 \mu \mathrm{g} \mathrm{Cd}$ per $\mathrm{kg}$ of egg) is consistent with this last value, and also with the $\mathrm{LD}_{50}$ for chicks established at $3.9 \mu \mathrm{g} \mathrm{Cd} / \mathrm{egg}(62 \mu \mathrm{g} \mathrm{Cd} / \mathrm{kg}$ of egg) in a similar in ovo experiment (Dżugan et al., 2011) and $3 \mu \mathrm{g} / \mathrm{egg}$ for cadmium salt injection into the air cell on day 2 of incubation (Gilani and Alibhai, 1990). Moreover, Kensova et al. (2015) found that the administration of cadmium nanoparticles onto the chorioallantoic membrane resulted in $100 \%$ mortality after $24 \mathrm{~h}$ for $500 \mu \mathrm{g} \mathrm{Cd} / \mathrm{egg}$.

Raising the dose of cadmium ions from 0 to $30 \mu \mathrm{g}$ per egg increased the mortality of duck embryos, which supports the findings of other research (Thompson and Bannigan, 2008; Dżugan et al., 2011). The toxic effect was particularly evident in the first 48 -h period after injection and indicated that Muscovy duck embryos at this stage of development seem to be much less sensitive to in ovo manipulation than chick embryos (Dżugan et al., 2011).

The malformations and malpositions detected in embryos that died during late stages can also be induced by heavy metal contamination (Herring et al., 2010). They appeared with similar frequency in the control and experimental groups and it cannot be excluded that they are due to genetic and environmental factors (Romanoff, 1972) or manipulation (Trzeciak et al., 2014). On the other hand, Kertész and Fáncsi (2003) found that Cd caused an increase in mortality and developmental anomalies of mallard duck embryos. Moreover, treating avian embryos with Cd always resulted in feather malformations (Narbaitz et al., 1983) and strong body malformations (Thompson and Bannigan, 2008; Cullinane et al., 2009), underdevelopment (dwarfism) (Dżugan et al., 2011), and kidney and hepatic dystrophy (Kertész and Fáncsi, 2003; Thompson and Bannigan, 2008).

Accumulation of cadmium in the kidney and liver disturbs the function of these organs, which is accompanied by an increase in the excretion of lysosomal enzymes (Järup et al., 1998; Fotakis et al., 2005; Thomas et al., 2009). This phenomenon can be explained by irreversible damage at the cellular level, where mitochondria are injured and the electron transfer chain is inhibited (Wang et al., 2004). Cells of the proximal convoluted tubules are very sensitive to hypoxia, 
which leads to their dysfunction (Haase, 2013). On the other hand, the impact of cadmium on lysosomes, despite its multiplexing, can lead to lysosomal membrane destabilisation, resulting in an efflux of lysosomal enzymes into body fluids (blood, urine) (Fotakis et al., 2005; Thomas et al., 2009). This is confirmed by our unpublished results obtained in electron microscopic (TEM) studies on organs of chicks treated with $\mathrm{Cd}$ in ovo. It has been demonstrated that even a low Cd exposure $(2 \mu \mathrm{g} / \mathrm{egg})$ caused severe mitochondrial damage and increasing the number of primary and secondary lysosomes in the liver and kidney (unpublished data). In humans, $\mathrm{N}$-acetylglucosaminidase, the most active lysosomal glycosidase, is commonly used as the most sensitive marker of cadmium-induced kidney damage (Thomas et al., 2009; Nordberg, 2010). It was shown that cadmium administration into eggs in doses exceeding $7.5 \mu \mathrm{g} \mathrm{Cd} /$ egg caused a significant increase in the few lysosomal acid glycosidases (NAG, $\alpha-G A L, \alpha-M A N$, $\beta$-MAN and $\beta$-GAL) as well as arylsulphatase. These findings are in agreement with the results of earlier studies where in ovo exposure of chicken embryos to cadmium resulted in increased activity of some lysosomal hydrolases (including NAG, $\beta$-MAN and ARYL) in the blood plasma of one-day-old chicks (Dżugan et al., 2011). Moreover, in the current experiment there was a very intensive increase in blood plasma ALT as well as AST activity, indicating cadmiuminduced damage of the liver in ducklings (Fig. 2). Such significant enhancement of aminotransferase activity is characteristic of chick embryos treated with cadmium in ovo (Kertész and Fáncsi, 2003; Pawlak et al., 2013). In humans, both of these aminotransferases are most commonly used in the differential diagnosis of various liver diseases where the AST/ALT ratio (De Ritis ratio) provides additional clinical insight. ALT is found predominantly in the liver, with clinically negligible quantities occurring in other tissues, while AST is found in the liver, heart (cardiac muscle), skeletal muscle, kidneys, brain, and red blood cells. As a result, ALT is a more specific indicator of liver dysfunction than AST (Rej, 1989), so the results obtained in this study confirmed the harmful action of cadmium on the liver in ducklings.

In conclusion, the results confirmed the dose-dependent toxic impact of cadmium on avian embryogenesis. The increase in blood plasma activities of NAG, $\beta$-MAN and ARYL in day-old ducklings indicates cadmium-induced damage of the kidneys and liver. Based on the calculated $\mathrm{LD}_{50}$ value and changes in the activity of the hydrolases studied, duck embryos seem to be less sensitive to cadmium exposure than chicken embryos. However, due to higher exposure in the aquatic environment the risk of cadmium contamination causing reproductive toxicity in aquatic birds should be considered. 


\section{Acknowledgements}

This work was supported by the research projects NN 304291140 and DS 3210/ZWRDZ of the University of Agriculture in Krakow.

\section{References}

Cullinane, J., Bannigan, J. and Thompson, J. (2009): Cadmium teratogenesis in the chick: Period of vulnerability using the early chick culture method, and prevention by divalent cations. Reprod. Toxicol. 28, 335-341.

Dobrzański, Z., Opaliński, S., Dobicki, W. and Usydus, Z. (2004): The accumulation of heavy metals in egg's content of laying hens housed in free range system in agricultural and industrial regions [in Polish, with English abstract]. Zesz. Nauk. AR Wroc. Zoot. 488, 87-91.

Dżugan, M., Lis, M., Droba, M. and Niedziółka, J. W. (2011): Effect of cadmium injected in ovo on hatching results and the activity of plasma hydrolytic enzymes in newly hatched chicks. Acta Vet. Hung. 59, 337-347.

Dżugan, M., Lis, M. W., Droba, M. and Niedziółka, J. W. (2012a): Protective effect of zinc on cadmium embryotoxicity and antioxidant status of blood plasma in newly hatched chicks. J. Environ. Sci. Health A Tox. Hazard Subst. Environ. Eng. 47, 1288-1293.

Dżugan, M., Zielińska, S., Hęclik, J., Pieniążek, M. and Szostek, M. (2012b): Evaluation of heavy metals environmental contamination based on their concentrations in tissues of wild pheasant (Phasianus colchicus L.). J. Microbiol. Biotechnol. Food Sci. 2, 238-245.

Fotakis, G., Cemeli, E., Anderson, D. and Timbrell, J. A. (2005): Cadmium chloride-induced DNA and lysosomal damage in hepatoma cell line. Toxicol. in Vitro 19, 481-489.

Gilani, S. H. and Alibhai, Y. (1990): Teratogenicity of metals to chick embryos. J. Toxicol. Environ. Health 30, 23-31.

Hamilton, M. A., Russo, R. C. and Thurston, R. V. (1977): Trimmed Spearman-Kärber method for estimating median lethal concentrations in toxicity bioassays. Environ. Sci. Technol. 11, 714-719.

Haase, V. H. (2013): Mechanisms of hypoxia responses in renal tissue. J. Am. Soc. Nephrol. 24, $537-541$.

Herring, G., Ackerman, J. T. and Eagles-Smith, C. A. (2010): Embryo malposition as a potential mechanism for mercury-induced hatching failure in bird eggs. Environ. Toxicol. Chem. 29, 1788-1794.

Järup, L., Berglund, M., Elinder, C. G., Nordberg, G. and Vahter, M. (1998): Health effects of cadmium exposure: A review of the literature and risk estimate. Scand. J. Work Environ. Health 24, 1-51.

Kalisińska, E., Salicki, W., Mysłek, P., Kavetska, K. M. and Jackowski, A. (2004): Using the mallard to biomonitor heavy metal contamination of wetlands in north-western Poland. Sci. Tot. Environ. 320, 145-161.

Kensova, R., Blazkova, I., Vaculovicova, M., Milosavljevic, V., Blazkova, L., Hynek, D., Kopel, P., Novotna, M., Zehnalek, J., Pohanka, M., Trnkova, L., Adam, V. and Kizek, R. (2015): The effect of cadmium ions and cadmium nanoparticles on chicken embryos and evaluation of organ accumulation. Int. J. Electrochem. Sci. 10, 3623-3634.

Kertész, V. and Fáncsi, T. (2003): Adverse effects of (surface water pollutants) $\mathrm{Cd}, \mathrm{Cr}$ and $\mathrm{Pb}$ on the embryogenesis of the mallard. Aquatic Toxicol. 65, 425-433.

Kim, J. and Oh, J. M. (2014): Trace element concentrations in eggshells and egg contents of blacktailed gull (Larus crassirostris) from Korea. Ecotoxicology 23, 1147-1152. 
Lucia, M., André, J. M., Bernadet, M. D., Gontier, K., Gérard, G. and Davail, S. (2010): Concentrations of metals (zinc, copper, cadmium, and mercury) in three domestic ducks in France: Pekin, Muscovy, and Mule ducks. J. Agric. Food Chem. 56, 281-288.

Marettová, E., Maretta, M. and Legáth, J. (2015): Toxic effects of cadmium on testis of birds and mammals: A review. Anim. Reprod. Sci. 155, 1-10.

Narbaitz, R., Riedel, K. D. and Kacew, S. (1983): Induction of feather malformations in chick embryos by cadmium: Protection by zinc. Teratology 27, 207-213.

Nordberg, G. F. (2010): Biomarkers of exposure, effects and susceptibility in humans and their application in studies of interactions among metals in China. Toxicol. Lett. 192, 45-49.

Pawlak, K., Dżugan, M., Wojtysiak, D., Lis, M. and Niedziółka, J. (2013): Effect of in ovo injection of cadmium on chicken embryo heart. Afr. J. Agric. Res. 8, 1534-1539.

Rahman, M. S., Sasanami, T. and Mori, M. (2007): Effects of cadmium administration on reproductive performance of Japanese quail (Coturnix japonica). J. Poult. Sci. 44, 92-97.

Rej, R. (1989): Aminotransferases in disease. Clin. Lab. Med. 9, 667-687.

Romanoff, A. L. (1972): Pathogenesis of the Avian Embryo. An Analysis of Causes of Malformations and Prenatal Death. Wiley-Interscience, New York, USA. 476 pp.

Sarkar, A., Ravindran, G. and Krishnamurty, V. (2013): A brief review on the effect of cadmium toxicity. Int. J. Biotech. Res. 3, 17-36.

Satarug, S., Baker, J. R., Urbenjapol, S., Haswell-Elkins, M., Reilly, E. B., Wiliams, D. J. and Moore, M. R. (2003): A global perspective on cadmium pollution and toxicity in nonoccupationally exposed population. Toxicol. Lett. 137, 65-83.

Sato, S., Okabe, M., Emoto, T., Kurasaki, M. and Kojima, Y. (1997): Restriction of cadmium transfer to eggs from laying hens exposed to cadmium. J. Toxicol. Environ. Health 51, 15-22.

Thomas, L. D. K., Hodgson, S., Nieuwenhuijsen, M. and Järup, L. (2009): Early kidney damage in a population exposed to cadmium and other heavy metals. Environ. Health Perspect. 117, $181-184$.

Thompson, J. and Bannigan, J. (2008): Cadmium: Toxic effects on the reproductive system and the embryo. Review. Reprod. Toxicol. 25, 304-315.

Thompson, J., Doi, T., Power, E., Balasubramanian, I., Puri, P. and Bannigan, J. (2010): Evidence against a direct role for oxidative stress in cadmium-induced axial malformation in the chick embryo. Toxicol. Appl. Pharmacol. 243, 390-398.

Toman, R., Massányi, P., Lukác, N., Ducsay, L. and Golian, J. (2005): Fertility and content of cadmium in pheasant (Phasianus colchicus) following cadmium intake in drinking water. Ecotoxicol. Environ. Saf. 62, 112-117.

Trzeciak, K. B., Lis, M. W., Sechman, A., Płytycz, B., Rudolf, A., Wojnar, T. and Niedziółka, J. W. (2014): Course of hatch and developmental changes in thyroid hormone concentration in blood of chicken embryo following in ovo riboflavin supplementation. Turkish J. Vet. Anim. Sci. 38, 230-237.

Tsipoura, N., Burger, J., Newhouse, M., Jeitner, C., Gochfeld, M. and Mizrahi, D. (2011): Lead, mercury, cadmium, chromium, and arsenic levels in eggs, feathers, and tissues of Canada geese of the New Jersey Meadowlands. Environ. Res. 111, 775-784.

Vodela, J. K., Lenz, S. D., Renden, J. A., McElhenney, W. H. and Kemppainen, B. W. (1997): Drinking water contaminants (arsenic, cadmium, lead, benzene, and trichloroethylene). 2. Effects on reproductive performance, egg quality, and embryo toxicity in broiler breeders. Poultry Sci. 76, 1493-1500.

Wang, Y., Fang, J., Leonard, S. S. and Krishna-Rao, K. M. (2004): Cadmium inhibits the electron transfer chain and induces oxygen species. Free Radic. Biol. Med. 36, 1434-1443.

Yamamoto, F. Y., Filipak Neto, F., Freitas, P. F., Oliveira Ribeiro, C. A. and Ortolani-Machado, C. F. (2012): Cadmium effects on early development of chick embryos. Environ. Toxicol. Pharmacol. 34, 548-555. 